Article

\title{
Transcriptome Sequencing and Development of Genic SSR Markers of an Endangered Chinese Endemic Genus Dipteronia Oliver (Aceraceae)
}

\author{
Tao Zhou ${ }^{1}$, Zhong-Hu Li ${ }^{1}$, Guo-Qing Bai ${ }^{1,2}$, Li Feng ${ }^{1}$, Chen Chen ${ }^{1,+}$, Yue Wei ${ }^{1,+}$, \\ Yong-Xia Chang ${ }^{1,+}$ and Gui-Fang Zhao ${ }^{1, *}$ \\ 1 Key Laboratory of Resource Biology and Biotechnology in Western China (Ministry of Education), \\ College of Life Sciences, Northwest University, Xi'an 710069, China; woody196@163.com (T.Z.); \\ lizhonghu@nwu.edu.cn (Z.-H.L.); bgq@ms.xab.ac.cn (G.-Q.B.); jjfl.007@163.com (L.F.); \\ Estelleplus@163.com (C.C.); weiyue0101@sina.com (Y.W.); changyongxia_mia@sina.com (Y.-X.C.) \\ 2 Xi'an Botanical Garden of Shaanxi Province, Xi'an 710061, China \\ * Correspondence: gfzhao@nwu.edu.cn; Tel.: +86-29-8830-5264 \\ + These authors contributed equally to this work.
}

Academic Editor: Derek J. McPhee

Received: 11 December 2015 ; Accepted: 26 January 2016 ; Published: 23 February 2016

\begin{abstract}
Dipteronia Oliver (Aceraceae) is an endangered Chinese endemic genus consisting of two living species, Dipteronia sinensis and Dipteronia dyeriana. However, studies on the population genetics and evolutionary analyses of Dipteronia have been hindered by limited genomic resources and genetic markers. Here, the generation, de novo assembly and annotation of transcriptome datasets, and a large set of microsatellite or simple sequence repeat (SSR) markers derived from Dipteronia have been described. After Illumina pair-end sequencing, approximately 93.2 million reads were generated and assembled to yield a total of 99,358 unigenes. A majority of these unigenes $(53 \%, 52,789)$ had at least one blast hit against the public protein databases. Further, 12,377 SSR loci were detected and 4179 primer pairs were designed for experimental validation. Of these 4179 primer pairs, 435 primer pairs were randomly selected to test polymorphism. Our results show that products from 132 primer pairs were polymorphic, in which 97 polymorphic SSR markers were further selected to analyze the genetic diversity of 10 natural populations of Dipteronia. The identification of SSR markers during our research will provide the much valuable data for population genetic analyses and evolutionary studies in Dipteronia.
\end{abstract}

Keywords: Dipteronia; transcriptome sequencing; de novo assembly; genic SSR; genetic diversity

\section{Introduction}

Dipteronia Oliver (Aceraceae) [1] is an endangered endemic genus found in southwestern and central China with only two living species, D. sinensis Oliver and D. dyeriana Henry [2]. Both species are members of the order Sapindales and family Aceraceae and are perennial woody plants with different natural ranges. In particular, $D$. sinensis is mainly found in central and southwestern China, whereas D. dyeriana is only located in the Yunnan Province in southwestern China. Fossil records indicate species of this genus also grew in North America during the Tertiary period [3]. Presently, the two living species have small population sizes due to deforestation and weak natural regeneration. D. sinensis and D. dyeriana are listed among Chinese Rare and Endangered Plants and China Species Red List with regard to being endangered, respectively [4].

Although D. sinensis and D. dyeriana live in different natural habitats, they still share some morphological similarities such as leaf shape and fruit character, although the mechanism of their 
divergent evolution remains unclear up to now. Therefore, to explore the genetic divergence between $D$. sinensis and D. dyeriana as well as to infer the genetic diversity of these species is still a valuable objective for us. Furthermore, it is also meaningful to trace the evolutionary dynamics of these two tertiary relict plants. Previous studies of Dipteronia have focused on universal genetic markers, morphologic divergence and/or seed physical and chemical properties [5-8] and only few genetic diversity studies were analyzed based on AFLP and cpSSR [9,10]. However, studies on speciation, demographic history, genomic variation and adaptive divergence of Dipteronia were not widely conducted, possibly due to limited genomic resources and genetic markers. So far only 116 nucleotide sequences from Sanger sequencing of Dipteronia have been deposited in the NCBI database and no ESTs were available yet. Hence, enriched genomic resources and genetic markers are much needed in order to decipher the genomic variation within the genus and investigate the genetic diversity in Dipteronia.

Due to their codominant and highly polymorphic nature, simple sequence repeats (SSRs) were commonly used for genetic diversity analyses and evolutionary studies [11-19]. Nevertheless, up to date, only a limited number of genomic SSRs were identified in Dipteronia according to the traditional FIASCO protocol $[20,21]$. No genic SSRs were developed yet. Therefore, it has become necessary to develop genic SSR markers for exploring genetic diversity and population structure of Dipteronia with neoteric technology.

Next-generation sequencing has greatly advanced our opportunities to obtain genome sequences and has also been widely used for various purposes in various species [22-26], but its application for large-scale population and phylogenetic studies is hindered by large genome sizes, DNA variation, polyploidy, and gene redundancy. Transcriptome sequencing has been an alternative to whole-genome sequencing because it can target genomic regions with corresponding EST sequences which can be exploited to develop EST-SSR markers. It is superior to conventional methods for developing SSR markers which were laborious and only yielded a few useful markers. Therefore, transcriptome sequencing has become a more effective and less expensive way to develop microsatellite markers. Research on non-model species have been investigated by using transcriptome sequencing and a number of microsatellite markers have been developed in these species [27-34]. In general, the genomic SSRs derived from traditional approaches were neutral anonymous markers which are not suitable for the assessment of functional diversity [35]. However, genic SSRs derived from the transcriptome sequences may actually regulate gene expression and function, making them a valuable resource for genetic studies and assessing functional diversity [36]. Furthermore, the genic SSR markers are transferable among distantly related species, whereas the genomic SSRs are not suitable for this purpose [37]. Overall, valid markers generated from transcriptome datasets will not only be important genomic resources but also be essential to explore evolutionary history and population genetics in plants, especially in endangered species.

To the best of our knowledge, to date no studies have reported the transcriptome sequencing of Dipteronia. The current study presents the transcriptomic profiling of material from the young leaves and fruits of two Chinese endangered endemic species of Dipteronia by using Illumina paired-end sequencing technology. Subsequently, a large set of genic SSR markers were developed for Dipteronia from transcriptome sequences. Overall, the transcriptomic resources and genic SSR markers collected herein would help us to guide further evolutionary and population genetic studies in Dipteronia and other relative species.

\section{Results}

\subsection{De Novo Assembly of Illumina Sequencing Data}

After filtering and evaluating the raw reads, a total of 40.6 and 52.6 million reads were generated for D. sinensis and D. dyeriana, with $88.50 \%$ Q20 bases and $90.14 \%$ Q20 bases, respectively. The total length of the reads was approximately 9.4 gigabases $(\mathrm{Gb}$, Table 1$)$. The raw reads for $D$. sinensis and 
D. dyeriana were deposited in the NCBI Sequence Read Archive (SRA) under the accession numbers SRR2127986 and SRR2127991, respectively. Using the Trinity software, short read sequences from D. sinensis and D. dyeriana were assembled into $1,377,057$ contigs and $1,378,610$ contigs, respectively (Table 1). No or little difference was found in the contigs length of these two Dipteronia species (Figure 1). Using the paired end-joining, gap-filling and Trinity software, 52,351 and 53,983 unigenes were obtained from D. sinensis and D. dyeriana, respectively (Table 2). By further pooling and reassembling all the two individual pre-assembled unigene sets, 99,358 unigenes were recovered with a mean length of $783 \mathrm{bp}$ and N50 value of $1452 \mathrm{bp}$ (Table 2). The length distribution of unigenes for both species and combined non-redundant unigenes is consistent with the length distribution of contigs (Figure 1).
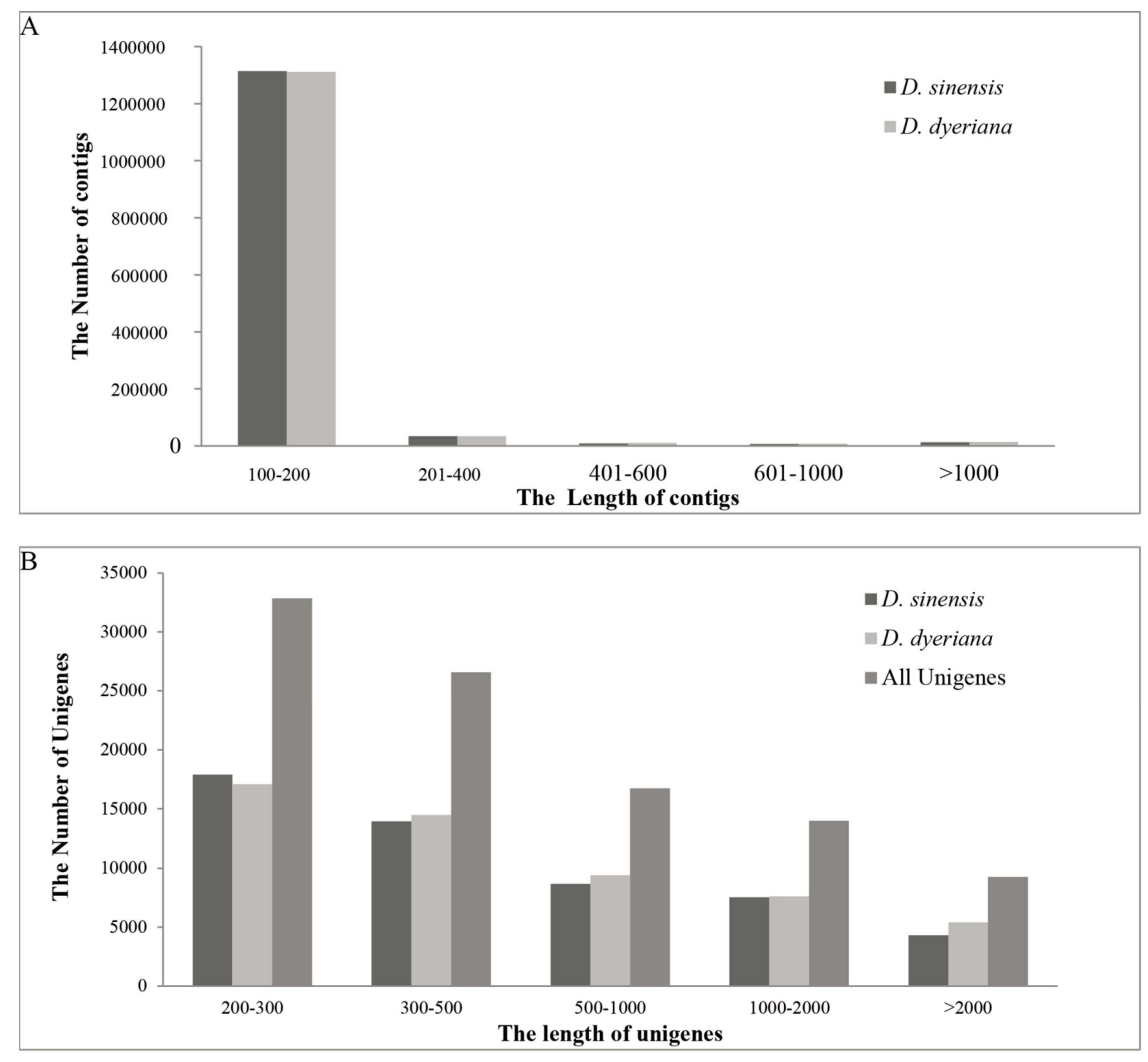

Figure 1. Length distribution of assembled contigs and unigenes. (A) Frequency distribution of the contig sizes from two Dipteronia species; (B) Size distribution of unigenes from two Dipteronia species.

Table 1. Basic information of transcriptome reads, assembled contigs and unigenes for two Dipteronia species.

\begin{tabular}{ccccccc}
\hline Species & Total Reads & $\begin{array}{c}\text { Total Length } \\
\text { of Reads }\end{array}$ & GC (\%) & Q20 (\%) & Number of Contigs & $\begin{array}{c}\text { Total Length } \\
\text { of Contigs }\end{array}$ \\
\hline D. sinensis & $40,615,432$ & $4,101,851,805$ & 45.50 & 88.50 & $1,377,057$ & $114,648,897$ \\
D. dyeriana & $53,620,610$ & $5,314,269,235$ & 45.21 & 90.14 & $1,378,610$ & $117,846,656$ \\
\hline
\end{tabular}

Table 2. Summary of the unigenes from two Dipteronia species.

\begin{tabular}{ccccc}
\hline Unigenes Source & $\begin{array}{c}\text { Total Number of } \\
\text { Unigenes }\end{array}$ & $\begin{array}{c}\text { Total Length of } \\
\text { Unigenes }\end{array}$ & $\begin{array}{c}\text { N50 of } \\
\text { Unigenes }\end{array}$ & $\begin{array}{c}\text { Mean Length of } \\
\text { Unigenes }\end{array}$ \\
\hline D. sinensis & 52,351 & $39,234,224$ & 1351 & 749 \\
D. dyeriana & 53,983 & $43,674,405$ & 1519 & 809 \\
All & 99,358 & $77,820,010$ & 1452 & 783 \\
\hline
\end{tabular}




\subsection{Functional Annotation for Non-Redundant Unigene Sequences}

The sequence similarity searching for the non-redundant unigenes demonstrated that 52,789 unigene sequences had at least one blast hit against non-redundant ( $\mathrm{Nr}$ ), Cluster of Orthologous Group (COG), Swiss-Prot, Kyoto Encyclopedia of Genes and Genomes (KEGG), or Gene ontology (GO) database. Of these annotated unigene sequences, 22,106 unigenes with a length over $1000 \mathrm{bp}$. A total of 52,597 sequences were annotated in the $\mathrm{Nr}$ database and the three top-hit species for $\mathrm{Nr}$ annotation were Theobroma cacao, Vitis vinfera, and Populus trichocarpa. Based on COG functional classification, 18,218 sequences were assigned to 25 COG categories (Figure S1). Among these categories, the cluster for general function prediction was the largest group (4730, 25.96\%); followed by translation, ribosomal structure and biogenesis $(2185,11.99 \%)$; replication, recombination and repair (2169, $11.91 \%)$; transcription $(1946,10.68 \%)$; posttranslational modification, protein turnover, chaperones $(1706,9.36 \%)$ and other classified groups. However, there were only five unigenes associated with nuclear structure but no unigenes were founded in the category of extracellular structures. For GO function, 43,345 unigene sequences were annotated based on sequence similarity. For the 14 level-2 categories in the cellular component category, cell part and cell were the most abundant terms; for the molecular function category, binding and catalytic activity were overrepresented among the 15 level-2 categories; for the biological process category, cellular process and metabolic process were the two most highly represented terms among the 23 level-2 categories (Figure 2). Using the Swiss-Prot database, 39,515 unigenes were annotated, and the minimum numbers of unigenes had blast hits against the KEGG database, since only 12,068 unigenes were annotated. With regard to the KEGG pathways analysis, the most representative were ribosome terms followed by glycolysis/gluconeogenesis and oxidative phosphorylation terms. Additionally, another KEGG pathway terms related to photosynthesis, respiration, terpenoid backbone biosynthesis, diterpenoid biosynthesis, anthocyanin biosynthesis and flavonoid biosynthesis were also recognized.

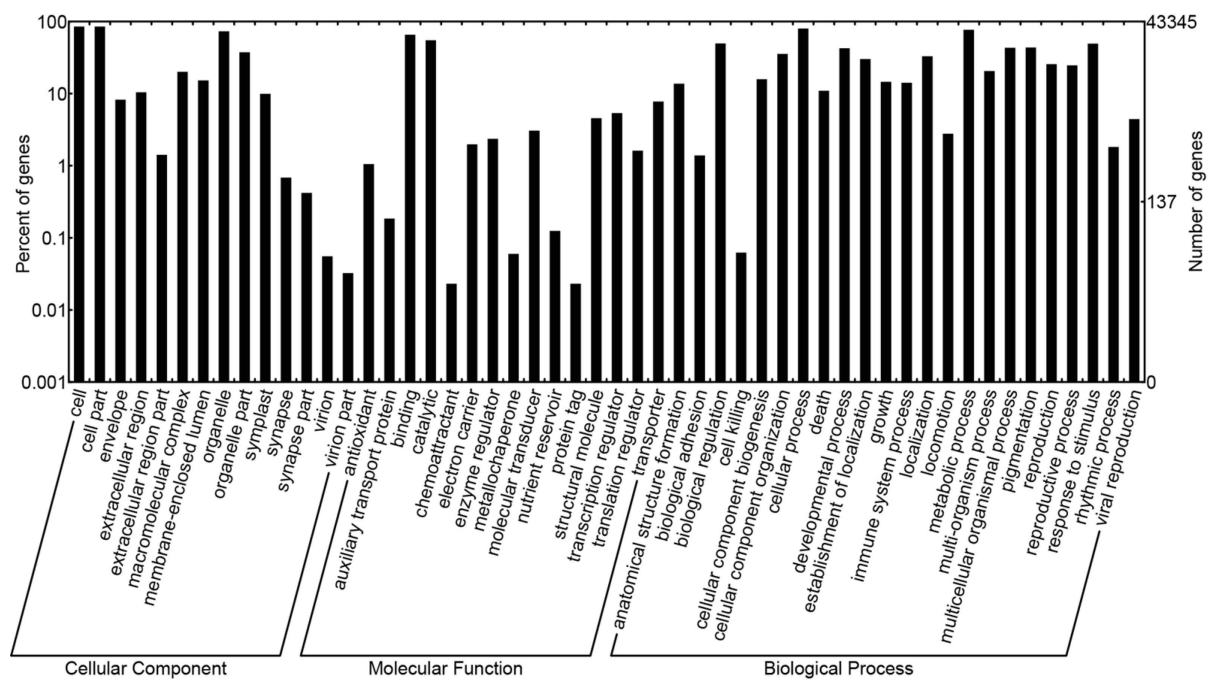

Figure 2. Gene Ontology (GO) classification of non-redundant unigene sequences from Dipteronia.

\subsection{Detection of SSR Loci, Development and Validation of Microsatellite Markers}

In this study, a total of $6321 / 6757 / 12377$ (D. sinensis / D. dyeriana/non-redundant unigenes) SSR loci were recognized using MISA perl script, of which 813/898/1658 unigene sequences contain more than one SSR. The average microsatellite density of the transcriptome in Dipteronia was one per $6207 \mathrm{bp} / 7780 \mathrm{bp} / 6287 \mathrm{bp}$ (Table 3 ). The most common type was di-nucleotide, followed by tri-nucleotide, hexa-nucleotide, penta-nucleotide and tetra-nucleotide (Figure 3). The number of repeat motifs per locus ranged from 5 to 12, in which SSRs with six repeats were the most abundant, followed 
by loci with five, seven and eight repeats. The number of SSR repeats of 12 was rare. The most abundant di-nucleotide repeat motif was AG/CT, followed by AT/AT, AC/GT; CG/GC was the least abundant. Among the tri-nucleotide repeat units, the dominant motif was AAG/CTT, followed by ATC/ATG and ACC/GGT (Figure 3).

Table 3. Summary of the microsatellite identified in the transcriptome.

\begin{tabular}{cccc}
\hline Category & D. Sinensis & D. Dyeriana & All Unigenes \\
\hline Total number of sequences examined & 52,351 & 53,983 & 99,358 \\
Total size of examined sequences (bp) & $39,234,224$ & $43,674,405$ & $77,820,010$ \\
Total number of identified SSRs & 6321 & 6757 & 12,377 \\
Number of SSR containing sequences & 5289 & 5614 & 10,253 \\
Number of sequences containing more than 1 SSR & 813 & 898 & 1658 \\
Number of SSRs present in compound formation ${ }^{\text {a }}$ & 29 & 27 & 717 \\
\hline
\end{tabular}

a The SSR locus contained at least two repeat motifs.
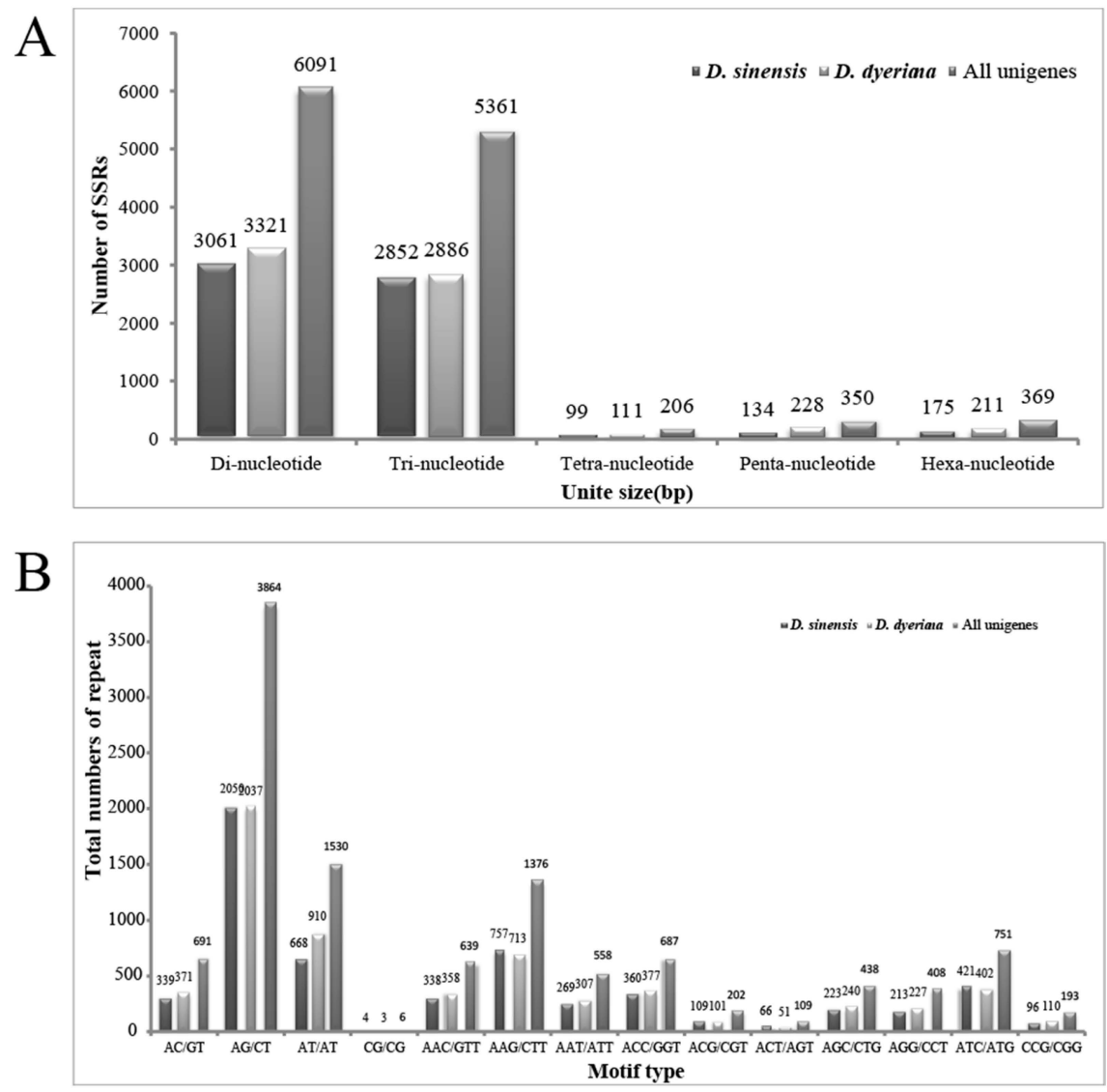

Figure 3. Frequency distribution of the SSRs identified in Dipteronia transcriptome. (A) Frequency distribution of the Dipteronia SSRs; (B) Total numbers of different SSR motifs in Dipteronia. Results of Di-nucleotides and Tri-nucleotides are represented.

In order to validate microsatellite loci detected from non-redundant unigenes, a total of 4179 primer pairs were designed using Primer3 based on the 10,253 unigene sequences derived from the combined non-redundant unigene database. A total of 435 primers were randomly selected and validated in multiple individuals for both species. 374 primer pairs (86\%) were successful in PCR amplification with genomic DNA from D. sinensis and D. dyeriana, whereas, the rest primer pairs failed to generate PCR products. Of the 374 primer pairs, 337 primer pairs amplified PCR products with the 
expected fragment size and the other 37 primer pairs produced fragments larger than the expected size. Afterward, all 337 SSR markers with the desired fragment size were screened in 44 individuals from both species to validate the polymorphism of the microsatellite markers. The results showed that 132 markers were polymorphic (Table S1). Of these 132 SSR markers, 91 SSR markers showed polymorphisms in $D$. sinensis, but monomorphism in D. dyeriana. Twenty-three SSR markers were polymorphic in D. dyeriana but monomorphic in D. sinensis. The remaining 18 loci showed high polymorphisms in both $D$. sinensis and D. dyeriana (Figure S2).

\subsection{Genetic Diversity Analysis of D. sinensis and D. dyeriana}

For evaluating the genetic diversity of Dipteronia, 44 individuals (Table 4) from 10 different natural populations of Dipteronia were collected and analyzed using 97 primer pairs selected from 132 polymorphic primer pairs. Based on 97 polymorphic primer pairs, the number of alleles $(\mathrm{Na})$ per locus ranged from two to 13 , with an average of 4.5 and the effective number of alleles per locus $(\mathrm{Ne})$ varied from 1.05 to 8.60 . The expected heterozygosity $\left(H_{E}\right)$ varied from 0.05 to 0.89 and observed heterozygosity $\left(H_{O}\right)$ ranged from 0 to 0.47 . Shannon's information index (I) values ranged from 0.11 to 2.24 with an average of 1.1.

Table 4. The information of 10 different populations used in genetic diversity analysis.

\begin{tabular}{ccccc}
\hline Population Code & Number of Individuals & Locations & Coordinates & Species \\
\hline BX & 4 & Baoxing, Sichuan & $30.54^{\circ} \mathrm{N}, 102.71^{\circ} \mathrm{E}$ & D. sinensis \\
CK & 4 & Chengkou, Chongqing & $32.04^{\circ} \mathrm{N}, 108.72^{\circ} \mathrm{E}$ & D. sinensis \\
FY & 4 & Fuyan, Guizhou & $27.34^{\circ} \mathrm{N}, 108.05^{\circ} \mathrm{E}$ & D. sinensis \\
FP & 4 & Foping, Shaanxi & $33.68^{\circ} \mathrm{N}, 107.98^{\circ} \mathrm{E}$ & D. sinensis \\
WJG & 4 & Wanjiagou, Hubei & $31.40^{\circ} \mathrm{N}, 110.55^{\circ} \mathrm{E}$ & D. sinensis \\
XE & 4 & Xuan'en, Hubei & $30.04^{\circ} \mathrm{N}, 109.67^{\circ} \mathrm{E}$ & D. sinensis \\
MZ & 5 & Mengzi, Yunan & $23.40^{\circ} \mathrm{N}, 103.78^{\circ} \mathrm{E}$ & D. dyeriana \\
CJZ & 5 & Chenjiazha, Yunan & $23.35^{\circ} \mathrm{N}, 103.97^{\circ} \mathrm{E}$ & D. dyeriana \\
ZCZ & 5 & Zhongcaozi, Yunan & $23.27^{\circ} \mathrm{N}, 103.45^{\circ} \mathrm{E}$ & D. dyeriana \\
PB & 5 & Pingbian, Yunan & $23.29^{\circ} \mathrm{N}, 103.88^{\circ} \mathrm{E}$ & D. dyeriana \\
\hline
\end{tabular}

Polymorphism information content (PIC) values ranged from 0.04 to 0.87 . The probabilities of deviation from Hardy-Weinberg equilibrium (HWE) proved that most of SSR markers did not significantly violate HWE (Table S2). A UPGMA dendrogram based on Nei's genetic distance showed that all the populations were divided into two clusters, cluster I for D. sinensis and cluster II for D. dyeriana (Figure 4). Genetic diversity analyses were also separately implemented in each species based on these 97 SSR loci and the results indicated that 76 SSR loci showed a higher polymorphism in D. sinensis but only 14 SSR markers showed a higher polymorphism in D. dyeriana (Tables S3 and S4).

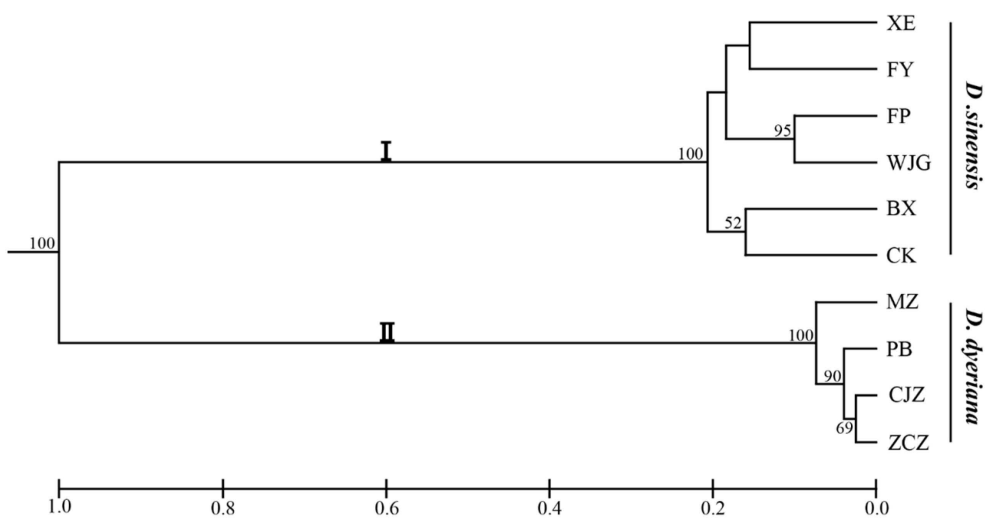

Figure 4. Dendrogram for 10 populations of Dipteronia from different areas based on 97 SSR loci. Bootstrap values ( $>50$ ) were labeled on the branches from 10,000 re-samplings. 


\section{Discussion}

\subsection{Sequences Assembly and Annotation of Dipteronia}

In the current study, similar numbers of unigene sequences were generated for both species after assembly, which was partly due to the fact the same tissues of both species were collected for sequencing. In parallel, the length distribution of contigs and unigenes in these two species was also coincidental, which indicated that the Illumina-based sequencing technology was successful and the assembly was relatively reliable. Therefore, the large number of unigenes obtained from this work could substantially increase the nearly non-existing genomic information of Dipteronia. In our sequence annotation attempt, more than half of the unigene sequences showed significant homology to genes in the $\mathrm{Nr}$ database. The relative high percentage of hits was partially caused by the increased number of long sequences in our unigene database (783 bp on average). In addition, our results indicated that $90.4 \%$ of unigenes over $1000 \mathrm{bp}$ in length showed homologous matches in the $\mathrm{Nr}$ database. This is consistent with previous studies that reported longer unigene sequences were more likely to have BLAST matches in the protein databases [38,39]. The rest of the unigenes could not be functionally annotated due to no blast hit against database or they were matched to unknown proteins. This is not unexpected since there is no available genomic and transcriptomic information for Dipteronia or a comprehensive genomic resource for Aceraceae, therefore, many genes of Dipteronia were not accessible. Many unigenes could be assigned to a wide range of GO and COG classification, which manifested transcriptome data for this study including diversified transcripts. Numerous subcategories related to metabolism were abundant in the KEGG pathway since leaves are the most important metabolic organ for chlorophytes, several pathways associated with photosynthesis and respiration were recognized. Strikingly, pathways associated with terpenoid backbone biosynthesis and diterpenoid biosynthesis were also identified in present study. Previous phytochemical studies of Dipteronia revealed that terpenoids could be isolated from fruits and branches [40,41]. Therefore, some of the transcripts identified in our study might be involved in the synthesis of these phytochemicals. Additional KEGG pathways like anthocyanin biosynthesis and flavonoid biosynthesis were also highlighted in our analyses, suggesting that the identified transcripts might be involved in these biosynthesis.

\subsection{Genic SSR Distribution and Frequency in Dipteronia Transcriptome}

Many studies have demonstrated that transcriptome sequencing was a powerful tool for identifying SSR markers. Various SSRs derived from transcriptome sequencing have been extensively used in plant genetic diversity analyses [42-44]. However, until now no genic SSRs were identified and used to evaluate genetic diversity for Dipteronia. In this study, a lot of unigene sequences that contained microsatellite loci were detected. The percentage of SSRs contained sequences was higher than pigeon pea, Cucurbita pepo and celery [44-46], but was similar to chickpea [27]. The discrepant SSRs frequency might be mainly caused by the parameters of tools for searching microsatellite loci. In this work, mononucleotide repeats were excluded for detecting SSRs since they could be caused by base mismatch or sequencing errors and they were difficult to distinguish from polyadenylation products. The mean density of SSR distribution was one microsatellite locus per $6.2 \mathrm{~kb} / 7.8 \mathrm{~kb} / 6.3 \mathrm{~kb}$. This density was less than the density in coffee $(1 / 2.16 \mathrm{~kb})$, and Amorphophallus $(1 / 3.63 \mathrm{~kb})[30,47]$, but it was higher than chickpea $(1 / 8.66 \mathrm{~kb})$ and Arabidopsis $(1 / 14 \mathrm{~kb})[48,49]$. The different distribution frequency of microsatellite loci may be partially related to genome composition, data size, and microsatellite screening criteria. Dinucleotide repeats were the most abundant repeat type in our study. This finding was in accordance with previous studies using sesame, pigeon pea and poplar [44,50-52] but inconsistent with other plant species such as cabbage, peanut and Brachiaria ruziziensis for which tri-nucleotide repeat motif was the most frequent in these species $[19,26,53]$. This difference may also be caused by different parameters for detecting microsatellite and different genome composition of each species. The dominant di-nucleotide and tri-nucleotide repeat motif of Dipteronia was AG/CT and AAG/CTT which was consistent with studies using rubber tree $[29,54]$. The lowest frequent motif 
was CG/CG which was also rare in studies using the plants such as coffee, wheat, Aspidistra saxicola, peach, corn, soybean, rice and pear [47,55-59].

\subsection{Polymorphic SSR Markers and Diversity Analyses of Dipteronia}

In the present study, the success rate of working primer pairs was relatively high as compared to previous studies in other plants $[34,45,50,60]$. This high success rate suggested that the assembled sequences of Dipteronia in our study were reliable and effective. Interestingly, some of working primers generated fragments larger than the expected size. It was probably due to the result of an insertion among the amplified regions. From 374 working primers, we obtained 132 polymorphic genic SSR markers with the polymorphic proportion of $35.2 \%$. The polymorphic rate of Dipteronia was lower than the previous studies using Houttuynia cordata (86\%) and Amorphophallus $(89.1 \%)$ [30,61]. Potentially, the lower polymorphic rate might be due to the limited sample sizes we collected and only two living species of this genus could be utilized. On the other hand, many of the primers that amplified discrete PCR bands from the two species did not show polymorphism in either species. After screening, we excluded 35 primers which showed polymorphism in one species but could not amplify unambiguous bands in another one, and then 97 primer pairs which showed high polymorphism were selected as genus-specific SSR markers to evaluate genetic diversity of Dipteronia. According to previous research, a PIC value greater than 0.5 generally indicates a highly polymorphic state [62]. In our study, 60 of these selected primers displayed PIC value greater than 0.5, indicating polymorphic SSR markers from this work were invaluable in marker-assisted Dipteronia genetic studies. The average alleles, in this study, were lower than genomic SSR markers from previous studies on D. sinensis (15.21) and D. dyeriana $(12.3)[20,21]$. This was partially due to the large sample sizes they used and the screening of genic SSRs with lower level of polymorphism in other research [44]. Genetic diversity analyses based on the selected polymorphic primers indicated that most of these SSR markers showed higher polymorphism in $D$. sinensis than that in $D$. dyeriana. It was probably because of the distribution range and natural populations of existing D. dyeriana are limited. According to the UPGMA analysis, we found that all populations were distinctly divided into two groups with bootstrap values of 100 (Figure 4). The result implied that there may exist high genetic variations or/and barriers between D. sinensis and D. dyeriana, which is consistent with previous studies based on cpSSR and AFLP $[9,10]$. In short, results from our study indicated the SSR markers from Diperonia transcriptome sequences are suitable and reliable. Therefore, our SSR markers derived from transcriptome sequences will be useful for detailed population genetic analyses of Dipteronia species.

\section{Experimental Section}

\subsection{Plant Materials}

Samples of $D$. sinensis and D. dyeriana for transcriptome sequencing were collected from the Botanic Garden in Xi'an, China and Kunming, China, in July 2014, respectively. Young leaves and fruits of an individual from both species were frozen in liquid nitrogen immediately and stored $-80{ }^{\circ} \mathrm{C}$ prior to RNA extraction. We also collected 44 individuals from six natural populations of $D$. sinensis and four natural populations of $D$. dyeriana, respectively. All sampled individuals from each population were spaced at least $50 \mathrm{~m}$ apart. These materials were dried with silica gel for DNA extraction, PCR amplification, and SSR markers validation.

\subsection{RNA Extracting, cDNA Library Construction and Illumina Paired-End Sequencing}

Total RNA was extracted using the EASY spin microRNA Rapid extraction kit (Aidlab Biotech, Beijing, China) and stored at $-80^{\circ} \mathrm{C}$ until further use. The RNA quality was determined by gel electrophoresis and NanoDrop 2000 Spectrophotometer (Thermo Fisher Scientific, Wilmington, DE, USA). Purified RNA from leaves and fruits was pooled together with equal volume to construct cDNA libraries for transcriptome sequencing. In brief, mRNA was enriched using the NEBNext 
Poly(A) mRNA Magnetic Isolation Module (E7490, NEB, Ipswich, UK) from $5 \mu \mathrm{g}$ of total RNA and sequencing libraries were prepared using NEBNext mRNA Library Prep Master Mix Set for Illumina (E6110, NEB,) and NEBNext Multiplex Oligos for Illumina (E7500, NEB,). Library insert sizes range from 100 to $200 \mathrm{bp}$. The insertion fragment sizes of prepared libraries were resolved on $1.8 \%$ agarose gel. Finally, size selected libraries were quantified using the Library Quantification Kit-Illumina GA Universal (KK4824, Kapa, Wilmington, DE, USA). The qualified libraries were amplified by bridge PCR to generate clustered template DNA fragments on the Illumina cbot. Ultimately, the clusters were sequenced on the Illumina Hiseq 2000 platform.

\subsection{De Novo Assembly, Analysis of Sequences and Functional Annotation}

Before assembly, the raw paired-end reads were filtered to obtain high-quality clean reads by removing adaptors, low-quality sequences (reads with unknown bases " $\mathrm{N}$ "), and reads with more than $20 \%$ low-quality bases (quality value $\leqslant 10$ ). The high quality reads of $D$. sinensis and $D$. dyeriana were further separately assembled using Trinity with default parameters [63]. Afterwards, all the assembled unigene sets were pooled and assembled into non-redundant unigenes using the TIGR Gene Indices Clustering (TGICL) tools and CD-HIT program [64,65]. The parameters of TGICL were set at a similarity of $95 \%$ and an overlap length of $40 \mathrm{bp}$ and the sequence identity cut-off for CD-HIT was set to 0.95 . Finally, all non-redundant unigenes were searched against the NCBI's non-redundant $(\mathrm{Nr})$ protein database, Cluster of Orthologous Group (COG), Swiss-Prot and the Kyoto Encyclopedia of Genes and Genomes (KEGG) pathway database with an E-value threshold of 1E-5. Gene ontology (GO) annotation was implemented on Blast2GO [66-68] with a cut-off E-value of 1E-5 and then plotted with functional classification using WEGO [69].

\subsection{Microsatellite Screening and Primer Design}

Microsatellite screening was performed using the MISA program [70] with parameters for identifying SSR as six for di-, five for tri- and tetra-, four for penta- and hexa-nucleotide motifs, respectively. Mono-nucleotide repeats were excluded in our analyses. Primers were designed using Primer3 [71]. The criteria for designing primers were as follows: PCR product size range of 100 to 300 bp; primer length of $18-21$ nucleotides; GC content of $40 \%-70 \%$ with $50 \%$ as optimum and annealing temperature between 50 and $70{ }^{\circ} \mathrm{C}$ with $55^{\circ} \mathrm{C}$ as the optimum melting temperature.

\subsection{DNA Isolation, PCR Amplification and SSR Validation}

Plant DNA was isolated from dried leaves of 44 individuals from different populations using the Plant Genomic DNA Kit (TianGen Biotech Co., Ltd., Beijing, China). Gel electrophoresis was performed using $1 \%$ agarose gel to check DNA integrity. All SSR primers were tested for amplification using DNA from the two species. PCR amplifications were performed in a reaction volume of $10 \mu \mathrm{L}$ with $5 \mu \mathrm{L} 2 \times$ Taq PCR Master Mix, $0.2 \mu \mathrm{M}$ of each primer, $1 \mu \mathrm{L}$ template DNA and $3.6 \mu \mathrm{L} \mathrm{ddH}_{2} \mathrm{O}$. All amplifications were carried out in SimpliAmp ${ }^{\text {TM }}$ Thermal Cycler (Applied Biosystems, Carlsbad, CA, USA) as follow: denaturation at $94{ }^{\circ} \mathrm{C}$ for $5 \mathrm{~min}$, followed by 30 cycles of $94{ }^{\circ} \mathrm{C}$ for $50 \mathrm{~s}$, at specific annealing temperature (Tm) for $30 \mathrm{~s}, 72^{\circ} \mathrm{C}$ for $40 \mathrm{~s}$ and $72{ }^{\circ} \mathrm{C}$ for $5 \mathrm{~min}$ as final extension. PCR products were resolved on $10 \%$ denaturing polyacrylamide gels and stained using a silver-staining protocol. The size of the DNA bands was determined by a PBR322 marker ladder (TianGen Biotech) and the alleles were scored using Quantity One Software v. 4.6.2 (Bio-Rad Laboratories, Hercules, CA, USA).

\subsection{Genetic Diversity Analysis and Microsatellite Scoring}

Genetic analyses for polymorphic loci were performed using GenAlEx 6.501 [72] to calculate parameters such as the number of alleles, effective number of alleles, expected heterozygosity, observed heterozygosity and Shannon's information index. The probabilities of deviation from Hardy-Weinberg equilibrium (HWE) for all microsatellite loci were determined using GenAlEx 6.501. CERVUS version 3.0.7 [73] was used to calculate the value of polymorphic information content (PIC) of each SSR 
primer. The UPGMA (unweighted pair-group method with arithmetic averaging) analysis based on Nei's (1987) genetic distances among populations was performed using TFPGA software [74]. Bootstrapping analysis (10,000 re-samplings) was carried out using the same software [74] in which bootstrap values over 50 were considered significant and provided on the dendrogram. In order to test the intra-specific polymorphisms of SSR loci in each species, genetic diversity of two species was also separately analyzed using GenAlEx 6.501 and CERVUS version 3.0.7.

\section{Conclusions}

Our study is the first to implement transcriptome sequencing in an endangered Chinese endemic genus by using NGS technology. We have identified a large set of genic SSR markers for Dipteronia based on transcriptome analysis. In this study, a total of 99,358 non-redundant unigenes were obtained after assembly. A total of 52,789 unigenes sequences had at least one blast hit against the $\mathrm{Nr}$, COG, Swiss-Prot, KEGG, or GO database. In addition, 12,377 microsatellite loci were detected from non-redundant unigenes and 4179 primer pairs were designed. We selected 435 primers to validate in multiple individuals of Dipteronia populations that resulted in 132 SSR polymorphic microsatellite markers. Our finding demonstrated that Illumina paired-end sequencing is a rapid and cost-effective way for identifying SSR markers in non-model organisms. The identified SSR markers are valuable for population genetic and evolutionary studies on Dipteronia.

Supplementary Materials: Supplementary materials can be accessed at: http:/ /www.mdpi.com/1420-3049/21/ 3/166/s1.

Acknowledgments: We acknowledge the staff of nature reserves for collecting plant materials for this study and we thank the researchers of $\mathrm{Xi}^{\prime}$ an and Kunming Botanical Garden for providing plant materials for RNA extraction. This study was co-supported by the Ph.D. Programs Foundation of Ministry of Education of China (Grand No. 20136101130001) and the National Natural Science Foundation of China (31470311). The authors declare that they have no competing interests. The authors alone are responsible for the content and writing of the paper.

Author Contributions: Gui-Fang Zhao and Tao Zhou conceived and designed the experiments. Tao Zhou, Yue Wei, Chen Chen and Yong-Xia Chang performed the experiments. Tao Zhou wrote the paper. Tao Zhou, Zhong-Hu Li, Guo-Qing Bai and Li Feng analyzed the data. All authors read and approved the final manuscript.

Conflicts of Interest: The authors declare no conflict of interest.

\section{References}

1. Oliver, D. Dipteronia sinensis. In Hooker's Icones Plantarum; 3rd Series; plate, England; 1889; Volume 9.

2. Henry, A. Chinese maples. Gard. Chron. 1903, 3, 21-22.

3. McClain, A.M.; Manchester, S.R. Dipteronia (Sapindaceae) from the Tertiary of North America and implications for the phytogeographic history of the Aceroideae. Am. J. Bot. 2001, 88, 1316-1325. [CrossRef] [PubMed]

4. Fu, L.K.; Jin, J.M. China Plant Red Data Book-Rare and Endangered Plants; Science Press: Beijing, China, 1992; Volume 1.

5. $\quad$ Ouyang, Z.Q.; Su, W.H.; Zhang, G.F. Studies on character of seed germination of rare plant Dipteronia dyeriana. Acta Bot. Yunnanica 2005, 28, 509-514.

6. Li, S.; Cai, Y.L.; Qian, Z.Q.; Zhao, G.F. Researches on the relationship between the morphological and genetic variations of Dipteronia dyeriana Henry (Aceraceae). Acta Ecol. Sin. 2003, 24, 925-931.

7. Li, S.; Qian, Z.Q.; Cai, Y.L.; Zhao, G.F. A comparison of the genetic diversity in Dipteronia sinensis Oliv and Dipteronia dyeriana Henry. Front. Biol. 2006, 1, 381-388. [CrossRef]

8. Shi, Y.N.; Zhou, Y.P.; Long, C.L.; Li, M.L.; Wang, Y.H.; Li, X.Y.; Guo, R.; Wang, H.S. Cycloheximide derivatives from the fruits of Dipteronia dyeriana. Helv. Chim. Acta 2009, 92, 1545-1549. [CrossRef]

9. Yang, J.; Qian, Z.Q.; Liu, Z.L.; Li, S.; Sun, G.L.; Zhao, G.F. Genetic diversity and geographical differentiation of Dipteronia Oliv. (Aceraceae) endemic to China as revealed by AFLP analysis. Biochem. Syst. Ecol. 2007, 35, 593-599. [CrossRef] 
10. Yang, J.; Li, S.; Sun, G.; Yuan, Y.; Zhao, G.F. Population structure and genetic variation in the genus Dipteronia Oliv. (Aceraceae) endemic to China as revealed by cpSSR analysis. Plant Syst. Evol. 2008, 272, 97-106. [CrossRef]

11. Hao, C.; Zhang, X.Y.; Wang, L.F.; Dong, Y.S.; Shang, X.W.; Jia, J.Z. Genetic diversity and core collection evaluations in common wheat germplasm from the Northwestern Spring Wheat Region in China. Mol. Breed. 2006, 17, 69-77. [CrossRef]

12. Barkley, N.A.; Roose, M.L.; Krueger, R.R.; Federici, C.T. Assessing genetic diversity and population structure in a Citrus germplasm collection utilizing simple sequence repeat markers (SSRs). Theor. Appl. Genet. 2006, 112, 1519-1531. [CrossRef] [PubMed]

13. Song, Z.; Xu, X.; Wang, B.; Chen, J.; Lu, B.R. Genetic diversity in the northernmost Oryza rufipogon populations estimated by SSR markers. Theor. Appl. Genet. 2003, 107, 1492-1499. [CrossRef] [PubMed]

14. Dirlewanger, E.; Cosson, P.; Tavaud, M.; Aranzana, M.; Poizat, C.; Zanetto, A.; Arús, P.; Laigret, F. Development of microsatellite markers in peach [Prunus. persica (L.) Batsch] and their use in genetic diversity analysis in peach and sweet cherry (Prunus avium L.). Theor. Appl. Genet. 2002, 105, 127-138. [PubMed]

15. Ali, M.; Rajewski, J.; Baenziger, P.; Gill, K.; Eskridge, K.; Dweikat, I. Assessment of genetic diversity and relationship among a collection of US sweet sorghum germplasm by SSR markers. Mol. Breed. 2008, 21, 497-509. [CrossRef]

16. Bucci, G.; Anzidei, M.; Madaghiele, A.; Vendramin, G. Detection of haplotypic variation and natural hybridization in halepensis-complex pine species using chloroplast simple sequence repeat (SSR) markers. Mol. Ecol. 1998, 7, 1633-1643. [CrossRef]

17. Karanth, K.P.; Avivi, A.; Beharav, A.; Nevo, E. Microsatellite diversity in populations of blind subterranean mole rats (Spalax ehrenbergi superspecies) in Israel: Speciation and Adaptation. Biol. J. Linn. Soc. 2004, 83, 229-241. [CrossRef]

18. Song, Z.; Zhu, W.; Rong, J.; Xu, X.; Chen, J.; Lu, B.R. Evidences of introgression from cultivated rice to Oryza rufipogon (Poaceae) populations based on SSR fingerprinting: Implications for Wild Rice Differentiation and Conservation. Evol. Ecol. 2006, 20, 501-522. [CrossRef]

19. Izzah, N.K.; Lee, J.; Jayakodi, M.; Perumal, S.; Jin, M.; Park, B.S.; Ahn, K.; Yang, T.J. Transcriptome sequencing of two parental lines of cabbage (Brassica oleracea L. var. capitata L.) and construction of an EST-based genetic map. BMC Genom. 2014, 15. [CrossRef] [PubMed]

20. Su, H.L.; Li, Z.H.; Zhao, P.; Bai, G.Q.; Zhou, T.H.; Liu, Z.L.; Zhao, G.F. Isolation and characterization of polymorphic microsatellite loci in the endangered plant Dipteronia sinensis (Sapindaceae). Am. J. Bot. 2012, 99, e425-e427. [CrossRef] [PubMed]

21. Chen, C.; Ren, B.B.; Xu, X.H.; Fu, C.X.; Qiu, Y.X. Isolation and characterization of microsatellite markers for Dipteronia dyerana (Sapindaceae), an endangered endemic species in China. Am. J. Bot. 2011, 98, e271-e273. [CrossRef] [PubMed]

22. Rai, H.S.; Mock, K.E.; Richardson, B.A.; Cronn, R.C.; Hayden, K.J.; Wright, J.W.; Knaus, B.J.; Wolf, P.G. Transcriptome characterization and detection of gene expression differences in aspen (Populus tremuloides). Tree Genet. Genomes 2013, 9, 1031-1041. [CrossRef]

23. Pedroni, M.; Sondgeroth, K.; Gallego-Lopez, G.; Echaide, I.; Lau, A. Comparative transcriptome analysis of geographically distinct virulent and attenuated Babesia bovis strains reveals similar gene expression changes through attenuation. BMC Genom. 2013, 14. [CrossRef] [PubMed]

24. Yoo, M.J.; Wendel, J.F. Comparative evolutionary and developmental dynamics of the cotton (Gossypium hirsutum) fiber transcriptome. PLoS Genet. 2014, 10, e1004073. [CrossRef] [PubMed]

25. Ma, H.Y.; Jiang, W.; Liu, P.; Feng, N.N.; Ma, Q.Q.; Ma, C.Y.; Li, S.J.; Liu, Y.X.; Qiao, Z.G.; Ma, L.B. Identification of transcriptome-derived microsatellite markers and their association with the growth performance of the mud crab (Scylla paramamosain). PLoS ONE 2014, 9, e89134. [CrossRef] [PubMed]

26. Silva, P.I.; Martins, A.M.; Gouvea, E.G.; Pessoa-Filho, M.; Ferreira, M.E. Development and validation of microsatellite markers for Brachiaria ruziziensis obtained by partial genome assembly of Illumina single-end reads. BMC Genom. 2013, 14. [CrossRef] [PubMed]

27. Agarwal, G.; Jhanwar, S.; Priya, P.; Singh, V.K.; Saxena, M.S.; Parida, S.K.; Garg, R.; Tyagi, A.K.; Jain, M. Comparative analysis of kabuli chickpea transcriptome with desi and wild chickpea provides a rich resource for development of functional markers. PLOS ONE 2012, 7, e52443. 
28. Wang, C.H.; Liu, X.J.; Peng, S.T.; Xu, Q.; Yuan, X.P.; Feng, Y.; Yu, H.Y.; Wang, Y.P.; Wei, X.H. Development of novel microsatellite markers for the BBCC Oryza genome (Poaceae) using high-throughput sequencing technology. PLoS ONE 2014, 9, e91826. [CrossRef] [PubMed]

29. Li, D.J.; Deng, Z.; Qin, B.; Liu, X.H.; Men, Z.H. De novo assembly and characterization of bark transcriptome using Illumina sequencing and development of EST-SSR markers in rubber tree (Hevea brasiliensis Muell. Arg.). BMC Genom. 2012, 13. [CrossRef]

30. Zheng, X.F.; Pan, C.; Diao, Y.; You, Y.N.; Yang, C.Z.; Hu, Z.L. Development of microsatellite markers by transcriptome sequencing in two species of Amorphophallus (Araceae). BMC Genom. 2013, 14. [CrossRef]

31. Wang, Z.; Yu, G.H.; Shi, B.B.; Wang, X.M.; Qiang, H.P.; Gao, H.W. Development and characterization of simple sequence repeat (SSR) markers based on RNA-Sequencing of Medicago Sativa and in silico mapping onto the M. truncatula genome. PLoS ONE 2014, 9, e92029.

32. Guo, R.; Mao, Y.R.; Cai, J.R.; Wang, J.Y.; Wu, J.; Qiu, Y.X. Characterization and cross-species transferability of EST-SSR markers developed from the transcriptome of Dysosma versipellis (Berberidaceae) and their application to population genetic studies. Mol. Breed. 2014, 34, 1733-1746. [CrossRef]

33. You, Y.N.; Liu, D.C.; Liu, H.B.; Zheng, X.F.; Diao, Y.; Huang, X.F.; Hu, Z.L. Development and characterisation of EST-SSR markers by transcriptome sequencing in taro (Colocasia esculenta (L.) Schoot). Mol. Breed. 2015, 35. [CrossRef]

34. Duan, C.X.; Li, D.D.; Sun, S.L.; Wang, X.M.; Zhu, Z.D. Rapid development of microsatellite markers for Callosobruchus chinensis using Illumina paired-end sequencing. PLoS ONE 2014, 9, e95458. [CrossRef] [PubMed]

35. Ai, B.; Gao, Y.; Zhang, X.; Tao, J.J.; Kang, M.; Huang, H.W. Comparative transcriptome resources of eleven Primulina Species, a group of "stone plants" from a biodiversity hot spot. Mol. Ecol. Resour. 2014, 15, 619-632. [CrossRef] [PubMed]

36. Zalapa, J.E.; Cuevas, H.; Zhu, H.; Steffan, S.; Senalik, D.; Zeldin, E.; McCown, B.; Harbut, R.; Simon, P. Using next-generation sequencing approaches to isolate simple sequence repeat (SSR) loci in the plant sciences. Am. J. Bot. 2012, 99, 193-208. [CrossRef] [PubMed]

37. Varshney, R.K.; Graner, A.; Sorrells, M.E. Genic microsatellite markers in plants: Features and Applications. TRENDS Biotechnol. 2005, 23, 48-55. [CrossRef] [PubMed]

38. Wang, S.F.; Wang, X.F.; He, Q.W.; Liu, X.X.; Xu, W.L.; Li, L.B.; Gao, J.W.; Wang, F.D. Transcriptome analysis of the roots at early and late seedling stages using Illumina paired-end sequencing and development of EST-SSR markers in radish. Plant. Cell Rep. 2012, 31, 1437-1447. [CrossRef] [PubMed]

39. Zhang, W.W.; Tian, D.K.; Huang, X.; Xu, Y.X.; Mo, H.B.; Liu, Y.B.; Meng, J.; Zhang, D.S. Characterization of flower-bud transcriptome and development of genic SSR Markers in Asian Lotus (Nelumbo nucifera Gaertn.). PLoS ONE 2014, 9, e112223. [CrossRef] [PubMed]

40. Guo, R.; Luo, M.; Long, C.L.; Li, M.L.; Ouyang, Z.Q.; Zhou, Y.P.; Wang, Y.H.; Li, X.Y.; Shi, Y.N. Triterpenoid ester saponins from Dipteronia dyeriana. Helv. Chim. Acta 2008, 91, 1728-1735. [CrossRef]

41. Shi, Y.N.; Wang, Y.P.; Guo, R.; Zhang, J.Y.; Wang, Y.Z.; Jin, H.; Long, C.L. Chemical constituents from the fruits of Dipteronia sinensis Oliv. J. Yunnan Agric. Univ. 2012, 4, 600-603.

42. Li, X.B.; Jin, F.; Jin, L.; Jackson, A.; Huang, C.; Li, K.H.; Shu, X.L. Development of Cymbidium ensifolium genic-SSR markers and their utility in genetic diversity and population structure analysis in Cymbidiums. BMC Genet. 2014, 15. [CrossRef] [PubMed]

43. Zhai, L.L.; Xu, L.; Wang, Y.; Cheng, H.; Chen, Y.L.; Gong, Y.Q.; Liu, L.W. Novel and useful genic-SSR markers from de novo transcriptome sequencing of radish (Raphanus sativus L.). Mol. Breed. 2014, 33, 611-624. [CrossRef]

44. Dutta, S.; Kumawat, G.; Singh, B.P.; Gupta, D.K.; Singh, S.; Dogra, V.; Gaikwad, K.; Sharma, T.R.; Raje, R.S.; Bandhopadhya, T.K.; et al. Development of genic-SSR markers by deep transcriptome sequencing in pigeonpea (Cajanus cajan (L.) Millspaugh). BMC Plant Biol. 2011, 11. [CrossRef] [PubMed]

45. Fu, N.; Wang, Q.; Shen, H.-L. De novo assembly, gene annotation and marker development using Illumina paired-end transcriptome sequences in celery (Apium graveolens L.). PLoS ONE 2013, 8, e57686.

46. Blanca, J.; Cañizares, J.; Roig, C.; Ziarsolo, P.; Nuez, F.; Picó, B. Transcriptome characterization and high throughput SSRs and SNPs discovery in Cucurbita pepo (Cucurbitaceae). BMC Genom. 2011, 12. [CrossRef] [PubMed] 
47. Aggarwal, R.K.; Hendre, P.S.; Varshney, R.K.; Bhat, P.R.; Krishnakumar, V.; Singh, L. Identification, characterization and utilization of EST-derived genic microsatellite markers for genome analyses of coffee and related species. Theor. Appl. Genet. 2007, 114, 359-372. [CrossRef] [PubMed]

48. Jhanwar, S.; Priya, P.; Garg, R.; Parida, S.K.; Tyagi, A.K.; Jain, M. Transcriptome sequencing of wild chickpea as a rich resource for marker development. Plant Biotechnol. J. 2012, 10, 690-702. [CrossRef] [PubMed]

49. Cardle, L.; Ramsay, L.; Milbourne, D.; Macaulay, M.; Marshall, D.; Waugh, R. Computational and experimental characterization of physically clustered simple sequence repeats in plants. Genetics 2000, 156, 847-854. [PubMed]

50. Du, Q.Z.; Gong, C.R.; Pan, W.; Zhang, D.Q. Development and application of microsatellites in candidate genes related to wood properties in the Chinese white poplar (Populus tomentosa Carr.). DNA Res. 2013, 20, 31-44. [CrossRef] [PubMed]

51. Zhang, H.Y.; Wei, L.B.; Miao, H.M.; Zhang, T.D.; Wang, C.Y. Development and validation of genic-SSR markers in sesame by RNA-seq. BMC Genom. 2012, 13. [CrossRef] [PubMed]

52. Wei, W.L.; Qi, X.Q.; Wang, L.H.; Zhang, Y.X.; Hua, W.; Li, D.H.; Lv, H.X.; Zhang, X.R. Characterization of the sesame (Sesamum indicum L.) global transcriptome using Illumina paired-end sequencing and development of EST-SSR markers. BMC Genom. 2011, 12. [CrossRef] [PubMed]

53. Zhang, J.N.; Liang, S.; Duan, J.L.; Wang, J.; Chen, S.L.; Cheng, Z.S.; Zhang, Q.; Liang, X.Q.; Li, Y.R. De novo assembly and characterisation of the transcriptome during seed development, and generation of genic-SSR markers in Peanut (Arachis hypogaea L.). BMC Genom. 2012, 13. [CrossRef] [PubMed]

54. Triwitayakorn, K.; Chatkulkawin, P.; Kanjanawattanawong, S.; Sraphet, S.; Yoocha, T.; Sangsrakru, D.; Chanprasert, J.; Ngamphiw, C.; Jomchai, N.; Therawattanasuk, K. Transcriptome sequencing of Hevea brasiliensis for development of microsatellite markers and construction of a genetic linkage map. DNA Res. 2011, 18, 471-482. [CrossRef] [PubMed]

55. Jung, S.; Abbott, A.; Jesudurai, C.; Tomkins, J.; Main, D. Frequency, type, distribution and annotation of simple sequence repeats in Rosaceae ESTs. Funct. Integr. Genomic. 2005, 5, 136-143. [CrossRef] [PubMed]

56. Gao, L.; Tang, J.; Li, H.; Jia, J. Analysis of microsatellites in major crops assessed by computational and experimental approaches. Mol. Breed. 2003, 12, 245-261. [CrossRef]

57. Yue, X.Y.; Liu, G.Q.; Zong, Y.; Teng, Y.W.; Cai, D.Y. Development of genic SSR markers from transcriptome sequencing of pear buds. J. Zhejiang Univ. Sci. B 2014, 15, 303-312. [CrossRef] [PubMed]

58. Nicot, N.; Chiquet, V.; Gandon, B.; Amilhat, L.; Legeai, F.; Leroy, P.; Bernard, M.; Sourdille, P. Study of simple sequence repeat (SSR) markers from wheat expressed sequence tags (ESTs). Theor. Appl. Genet. 2004, 109, 800-805. [CrossRef] [PubMed]

59. Huang, D.N.; Zhang, Y.Q.; Jin, M.D.; Li, H.; Song, Z.; Wang, Y.G.; Chen, J. Characterization and high cross-species transferability of microsatellite markers from the floral transcriptome of Aspidistra saxicola (Asparagaceae). Mol. Ecol. Resour. 2014, 14, 569-577. [CrossRef] [PubMed]

60. Kaur, S.; Cogan, N.; Pembleton, L.; Shinozuka, M.; Savin, K.; Materne, M.; Forster, J. Transcriptome sequencing of lentil based on second-generation technology permits large-scale unigene assembly and SSR marker discovery. BMC Genom. 2011, 12. [CrossRef] [PubMed]

61. Wei, L.; Li, S.H.; Liu, S.Q.; He, A.N.; Wang, D.; Wang, J.; Tang, Y.L.; Wu, X.J. Transcriptome analysis of Houttuynia cordata Thunb. by Illumina paired-end RNA sequencing and SSR marker discovery. PLoS ONE 2014, 9, e84105. [CrossRef] [PubMed]

62. Yadav, H.K.; Ranjan, A.; Asif, M.H.; Mantri, S.; Sawant, S.V.; Tuli, R. EST-derived SSR markers in Jatropha curcas L.: Development, Characterization, Polymorphism, and Transferability across the Species/Genera. Tree Genet. Genomes 2011, 7, 207-219. [CrossRef]

63. Grabherr, M.G.; Haas, B.J.; Yassour, M.; Levin, J.Z.; Thompson, D.A.; Amit, I.; Adiconis, X.; Fan, L.; Raychowdhury, R.; Zeng, Q.; et al. Full-length transcriptome assembly from RNA-Seq data without a reference genome. Nat. Biotechnol. 2011, 29, 644-652. [CrossRef] [PubMed]

64. Pertea, G.; Huang, X.; Liang, F.; Antonescu, V.; Sultana, R.; Karamycheva, S.; Lee, Y.; White, J.; Cheung, F.; Parvizi, B.; et al. TIGR Gene Indices clustering tools (TGICL): A Software System for Fast Clustering of Large EST Datasets. Bioinformatics 2003, 19, 651-652. [CrossRef] [PubMed]

65. Li, W.; Godzik, A. Cd-hit: A Fast Program for Clustering and Comparing Large Sets of Protein or Nucleotide Sequences. Bioinformatics 2006, 22, 1658-1659. [CrossRef] [PubMed] 
66. Conesa, A.; Götz, S.; García-Gómez, J.M.; Terol, J.; Talón, M.; Robles, M. Blast2GO: A Universal Tool for Annotation, Visualization and Analysis in Functional Genomics Research. Bioinformatics 2005, 21, 3674-3676. [CrossRef] [PubMed]

67. Ashburner, M.; Ball, C.A.; Blake, J.A.; Botstein, D.; Butler, H.; Cherry, J.M.; Davis, A.P.; Dolinski, K.; Dwight, S.S.; Eppig, J.T.; et al. Gene Ontology: Tool for the Unification of Biology. Nat. Genet. 2000, 25, $25-29$. [CrossRef] [PubMed]

68. Ye, J.; Fang, L.; Zheng, H.K.; Zhang, Y.; Chen, J.; Zhang, Z.J.; Wang, J.; Li, S.T.; Li, R.Q.; Bolund, L.; et al. WEGO: A Web Tool for Plotting GO Annotations. Nucleic Acids Res. 2006, 34, W293-W297. [CrossRef] [PubMed]

69. Kanehisa, M.; Goto, S. KEGG: Kyoto encyclopedia of genes and genomes. Nucleic Acids Res. 2000, 28, 27-30. [CrossRef] [PubMed]

70. Thiel, T.; Michalek, W.; Varshney, R.; Graner, A. Exploiting EST databases for the development and characterization of gene-derived SSR-markers in barley (Hordeum vulgare L.). Theor. Appl. Genet. 2003, 106, 411-422. [PubMed]

71. Rozen, S.; Skaletsky, H. Primer3 on the WWW for General Users and for Biologist Programmers. In Bioinformatics Methods and Protocols; Springer: Berlin, Germany, 1999; pp. 365-386.

72. Peakall, R.; Smouse, P.E. GenAlEx 6.5: Genetic Analysis in Excel. Population genetic software for teaching and research-An update. Bioinformatics 2012, 28, 2537-2539. [CrossRef] [PubMed]

73. Kalinowski, S.T.; Taper, M.L.; Marshall, T.C. Revising how the computer program CERVUS accommodates genotyping error increases success in paternity assignment. Mol. Ecol. 2007, 16, 1099-1106. [CrossRef] [PubMed]

74. Miller, M.P. Tools for population genetic analyses (TFPGA) 1.3: A Windows Program for the Analysis of Allozyme and Molecular Population Genetic Data. Available online: http:/ / www.marksgeneticsoftware.net/ tfpga.htm (accessed on 13 September 2015).

Sample Availability: All samples are available from the authors.

(C) 2016 by the authors; licensee MDPI, Basel, Switzerland. This article is an open access article distributed under the terms and conditions of the Creative Commons by Attribution (CC-BY) license (http://creativecommons.org/licenses/by/4.0/). 